Echinoderms. By David Nichols. Hutchinson and Co., Ltd. 12s. $6 d$.

Dr. David Nichols's book deals with several facets of the biology of the echinoderms (starfish, sea-urchins and relatives), but is not intended as a guide to their anatomy, which is adequately covered elsewhere. He gives a general account of the five main groups of living echinoderms and then goes on to discuss certain aspects of their biology which are of interest to him, such as the five-rayed symmetry and the tube-feet, both so characteristic of the echinoderms. Perhaps the most interesting parts of the book, and the most unusual, are the chapters which deal with the fossil forms. Most of these died out several hundred million years ago and it is often difficult for the biologist fully to understand their place in the ancestry of the starfishes, brittlestars and sea-urchins of to-day. This is an interesting and wellwritten book and should be of value to students and naturalists as a supplement to the more comprehensive, but less readable textbooks.

H. G. V.

Rowland Ward's Records of Big Game. Eleventh Edition (AFrica). Compiled and Edited by Gerald A. Best, Francois Edmond-Blanc, and R. Courtenay Witting. Rowland Ward Ltd. $£ 810$ s.

This latest edition brings up-to-date and amplifies what was recorded in the Tenth Edition, published in 1935, twenty-seven years ago. The Compilers and Editors are to be congratulated on having at long last, despite innumerable difficulties, brought their labours to a successful conclusion; it must have been a stupendous task. Apart from its value to sportsmen as an authoritative record of African game trophies of maximum size, this is also a useful work of reference for many others. Methods of how to take reliable measurements are carefully detailed, besides being well illustrated; but as these methods differ from those followed on the Continent and in America, this is a publication primarily for British sportsmen. For those who think of trophy measurements in centimeters rather than inches, a simple conversion table is provided. The emphasis is on the species, but where a well defined and generally accepted race or races exist, there are separate lists. The text is both informative and descriptive. The photographic section, with its sixty-five pictures of exceptional merit-selected from submissions by wild life photographers throughout the world-greatly enhances the value of this edition. One may have waited long for the "Eleventh" to materialize, but it has been well worth waiting.

C. R. S. P.

\title{
Animals of East Africa. By C. A. Spinage. Collins. 30s.
}

There could be no better testimony to the worth of this book than Sir Julian Huxley's comment, in a "Foreword", that the illustrations are " the best collection of wild life photographs I have ever seen"; high praise indeed. Not only are the illustrations of special merit, covering as they do an astounding variety of subjects-some original and unusual, but the carefully recorded observations on the behaviour of many creatures, great and small, have added considerably to our knowledge-admittedly still so imperfect - of wild nature. The author, by aptitude, has become an ardent student of African wild life, moreover he is a skilled photographer who has evidently made full use of the manifold opportunities which have come his way. Only those who have tried to do likewise can really appreciate the tedious hours of discomfort involved, and the inexhaustible patience 